\title{
A rare cause of abdominal pain in a child: Mesenteric panniculitis
}

\author{
Ishak Abdurrahman Isik* \\ Department of Paediatric Gastroenterology Hepatology and Nutrition, Antalya Education and Research Hospital, Muratpasa-Antalya, Turkey
}

\begin{abstract}
Mesenteric panniculitis is chronic inflammatory disease of mesenteric fatty tissue mostly seen in adults. Patients may be asymptomatic or may present with abdominal pain, bowel dysfunction, fever, nausea or vomiting or weight loss. Very few paediatric cases have been reported in the literature. We have reported a child presented as acute appendicitis who is diagnosed as mesenteric panniculitis after abdominal computerized tomography. We have observed complete resolution without any specific treatment in our case.
\end{abstract}

We recommend that this very rare condition should be taken into consideration in children with abdominal pain.

\section{Introduction}

Mesenteric panniculitis is chronic inflammatory disease of mesenteric fatty tissue mostly seen in adults [1]. Jura Back had been defined Mesenteric panniculitis (MP) first in 1924 [2]. MP is also known as lipomatosis or lipogranulouma of mesentery [3]. Males between 23-87 years of age (mean 60) are predominantly affected [2]. MP is characterised by inflammation of unknown aetiology of fatty tissue. Fibrosis and necrosis of fatty tissue is also seen in histological examination [2]. Small intestinal mesentery is the most commonly involved region of gastrointestinal system [1]. Patients may be asymptomatic or may present with abdominal pain, bowel dysfunction, fever, nausea or vomiting or weight loss. An abdominal mass may be detected on physical examination [2]. MP should be differentiated from intraabdominal tumors, mesenteric inflammatory pseudotumor and mesenteric fibromatosis [2].

Although adults are mostly affected, about 20 paediatric cases has been reported in the literature [4]. We want to report this rare condition seen in children to prevent unnecessary treatment and surgical procedures.

\section{Case}

A 16 years old male patient suffering from abdominal pain and vomiting for 10 days referred to our clinic. There was no history of trauma or any known disease. Mild abdominal pain around the umbilicus gradually increased to severe pain at the right side of the abdomen. On physical examination his weight and height were $80 \mathrm{~kg}$ and $165 \mathrm{~cm}$ respectively (weight for height was \%154 and his body mass index was $29.38 \mathrm{~kg} / \mathrm{m}^{2}$ ). There was an abdominal mass palpable at the right side of the umbilicus. An abdominal tenderness was also present at all quadrants of the abdomen. His complete blood cell count revealed, WBC: $11200 \mathrm{cell} / \mathrm{mm}^{3}$, Hbg: $13.1 \mathrm{~g} / \mathrm{dL}, \mathrm{Hct}$ \% 39.6 , platelet count: $405000 \mathrm{cell} / \mathrm{mm}^{3}$. Erythrocyte sedimentation rate (ESR) was $58 \mathrm{~mm} / \mathrm{h}$ and C-reactive protein (CRP) was $72 \mathrm{mg} / \mathrm{L}(0-5)$. His biochemical analysis and electrolyte levels were with in normal limits. He was hospitalised with the initial diagnosis of invagination or perforated appendicitis. His abdominal ultrasonography was not compatible with acute appendicitis. Whole abdominal computerized tomography $(\mathrm{CT})$ was performed. A mesenteric heterogeneous tumor like mass in the diameter of $7 \mathrm{x} 4 \mathrm{~cm}$ was detected on his abdominal CT (Figure 1). This hypo dens heterogeneous abdominal mass with specific fat ring sign was compatible with mesenteric panniculitis. $\mathrm{He}$ was hydrated intravenously and treated symptomatically. Analgesic and ondansetron were given for abdominal pain and vomiting respectively with antibiotics (methranidasole $15 \mathrm{mg} / \mathrm{kg} /$ day in two divided doses and ceftriaxone $50 \mathrm{mg} / \mathrm{kg} /$ day in two divided doses) treatment. His dyspeptic complaints were managed with proton pump inhibitor. $\mathrm{He}$ was followed up nil per oral for three days. After than he was well tolerated oral feeding. At the seventh day of treatment his WBC was $6300 \mathrm{cell} / \mathrm{mm}^{3}$, hgb was $14 \mathrm{gr} / \mathrm{dL}$, his platelet count was $158000 \mathrm{cell} /$ $\mathrm{mm}^{3}$, ESR was $24 \mathrm{~mm} / \mathrm{h}$ and CRP was $23 \mathrm{mg} / \mathrm{L}$. His complaints were completely recovered and was discharged at the eighth day of the treatment.

After two months, all of his complaints were recovered. There was no pathological finding on his physical examination and his control abdominal CT had been revealed complete resolution of the mesenteric mass (Figure 2).

\section{Discussion}

MP is chronic fibrosing inflammatory disease of the mesenteric fatty tissue of small intestine or colon [1]. Exact mechanism causing inflammation is still unknown [5]. Association with some malign,

${ }^{\star}$ Correspondence to: Ishak Abdurrahman Isik, Department of Paediatric Gastroenterology Hepatology and Nutrition, Antalya Education and Research Hospital, Muratpasa-Antalya, Turkey, Tel: +90 53246253 22; E-mail: Ishakisik02@yahoo.com.tr

Key words: abdominal pain, child, mesenteric panniculitis

Received: April 25, 2019; Accepted: May 13, 2019; Published: May 17, 2019 


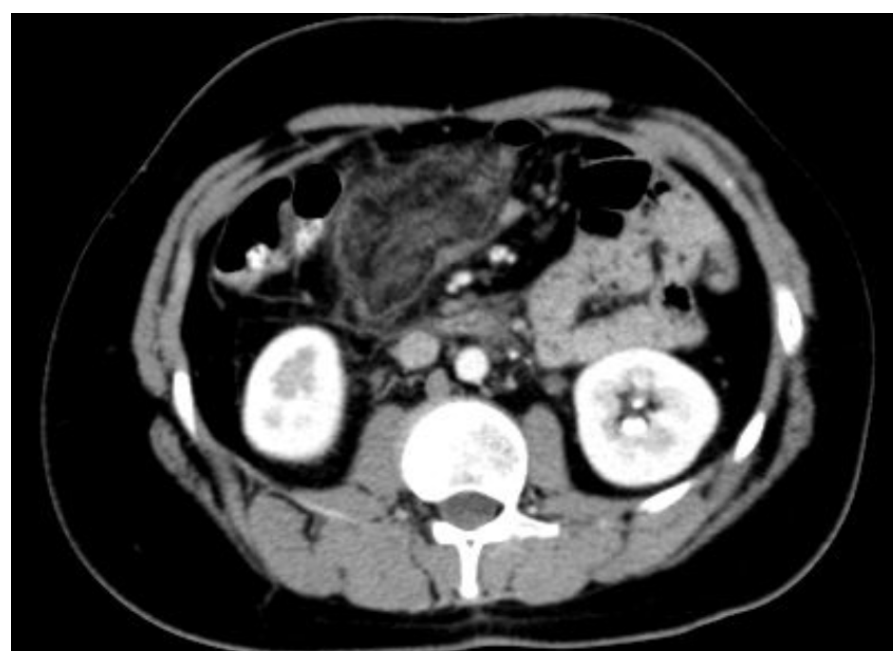

Figure 1. A hypodense heterogeneous mass with fat ring sign in the mesenteric fatty tisue at the right side of the umblicus

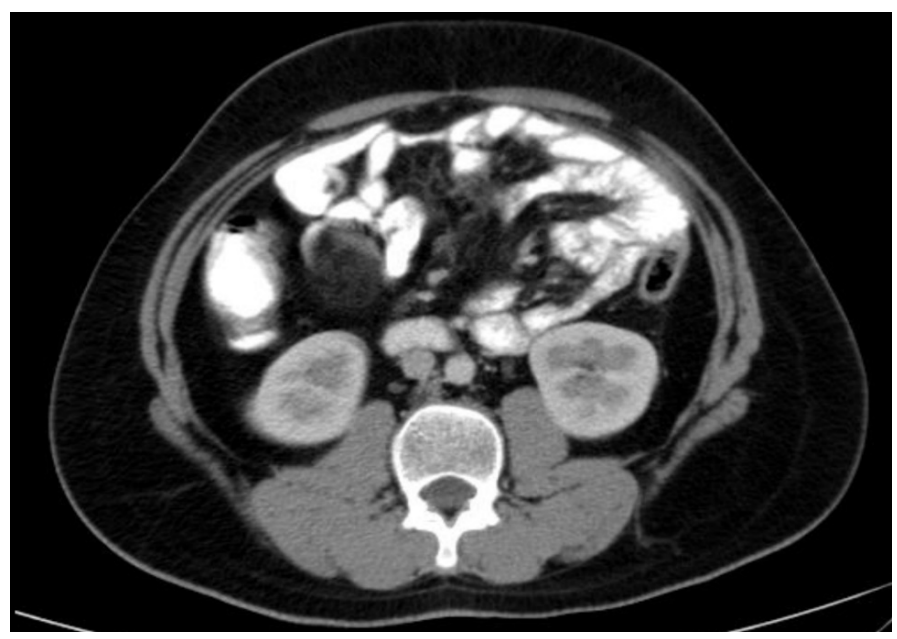

Figure 2. Complete resolution of the mass after two months

autoimmune or infectious diseases had been reported previously [1]. Kipfer et al. [6] had shown about $30 \%$ of patients with sclerosing mesenteritis also had a malignancy.

This rare disease is thought to affect about $1 \%$ of the population [7]. It mainly affects the adults. Only few child cases had been reported in the literature. Relatively small amount of the fatty tissue of the children thought to be the cause of the low frequency of the disease among children $[4,8]$. Abdominal pain, diarrhoea, nausea, malaise and weight loss are most common presenting symptoms $[1,8]$.

Biopsy is not required usually. Abdominal CT finding is very typical and thought to be the best procedure for the diagnosis of the MP [1]. In our case MP is diagnosed by abdominal CT. Due to clinical improvement during follow up period we had no need for further trial such as surgical removal or biopsy of the mass.

As in our case, MP is usually a benign disease and spontaneous remission could be achieved [9]. Different drug therapies (steroids, cholchicine, immunosuppressive drugs, progesterone) or surgery could be the choice of the treatment according to the patient $[1,4]$. As in our case, if obstruction symptoms are not present patients can be followed up only with symptomatic treatment for spontaneous remission.

\section{Conclusion}

This very rare condition should be taken into consideration in children with abdominal pain and abdominal tumor like mass.

\section{References}

1. Rumman N, Rumman G, Sharabati B, Zagha R, Disi N (2014) Mesenteric panniculitis in a child misdiagnosed as appendicular mass: a case report end review of literature. Springerplus 3: 73. [Crossref]

2. Hussein MR, Abdelwahed SR (2015) Mesenteric panniculitis: an update. Expert Rev Gastroenterol Hepatol 9: 67-78. [Crossref]

3. Schaffler A, Muller-Ladner U, Scholmerich J, Buchler C (2006) Role of adipose tissue as an inflammatory organ in human diseases. Endocr Rev 27: 449-467. [Crossref]

4. Tarca E, Trandafirescu MF, Cojocaru E, Mihaila D, Savu B (2017) Mesenteric panniculitis, a rare cause of acute surgical abdomen in children. Case report and literature review. Rom J Morphol Embryol 58: 1597-1604. [Crossref]

5. Issa I, Baydoun H (2009) Mesenteric panniculitis: various presentation and treatment regimens. World J Gastroenterol 15: 3827-3830. [Crossref]

6. Kipfer RE, Moertel CG, Dahlin DC (1974) Mesenteric lipodystrophy. Ann Intern Med 80: 582-588. [Crossref]

7. Nicholson JA, Smith D, Diab M, Scott MH (2010) Mesenteric panniculitis in Merseyside: a case series and a review of the literature. Ann R Coll Surg Engl 92: W31-34. [Crossref]

8. Akram S, Pardi D, Schaffner J, Smyrk T (2007) Sclerosing mesenteritis: clinical features, treatment, and outcome in ninety-two patients. Clin Gastroenterol Hepatol 5: 589-596. [Crossref]

9. Mazure R, Fernandez Marty P, Niveloni S, Pedreira S, Vazquez H, et al. (1998) Successful treatment of retractile mesenteritis with oral progesterone. Gastroenterology 114: 1313-1317. [Crossref]

Copyright: (C2019 Isik IA. This is an open-access article distributed under the terms of the Creative Commons Attribution License, which permits unrestricted use, distribution, and reproduction in any medium, provided the original author and source are credited. 